\title{
AVALIAÇÃO DAS COMPETÊNCIAS DOS PROFESSORES DE ENFERMAGEM PARA FACILITAR A APRENDIZAGEM DE ADULTOS*
}

\author{
Patricia Bover Draganoc ${ }^{1}$, Maria Cristina Sanna²
}

${ }^{1}$ Enfermeira e Arquiteta. Mestre em Ciências. Universidade Federal de São Paulo. São Bernardo do Campo, SP, Brasil.

${ }^{2}$ Enfermeira. Doutora em Enfermagem. Docente da Universidade Federal de São Paulo. São Paulo, SP, Brasil.

RESUMO: O objetivo desse estudo foi avaliar o desempenho que o enfermeiro docente de enfermagem atribui a si, na competência de facilitador da aprendizagem de adultos. Tratou-se de estudo descritivo, comparativo, transversal e quantitativo, desenvolvido com 226 docentes enfermeiros da graduação em enfermagem paulistana. Os dados foram colhidos de junho de 2010 a fevereiro de 2011, por meio de escala de Likert, lançados em planilha do Excel $^{\circledR}$ e analisados por meio de estatística descritiva e testes não-paramétricos de Wilcoxon e Friedman. Os professores se consideraram distantes do nível máximo das competências que almejavam alcançar, declararam maior domínio para o design e aplicação experiências de aprendizagem que da estrutura conceitual e teórica da aprendizagem de adultos. Os docentes se consideraram aquém do ideal nas competências para facilitar a aprendizagem.

DESCRITORES: Enfermagem; Educação superior; Docentes de enfermagem; Modelos educacionais.

\section{ASSESSMENT OF NURSING TEACHERS ABILITIES TO FACILITATE ADULT LEARNING}

\begin{abstract}
The aim of this study was to evaluate the performance that the nursing teacher assigns for himself, in his abilities as facilitator for adult's learning. It was a descriptive, comparative, transversal and quantitative study developed with 226 nursing teachers from the nursing graduation in São Paulo. Data were collected from June 2010 to February 2011, with the Likert scale, launched in Exce $^{\circledast}$ spreadsheet and analyzed using descriptive statistics and non-parametric Wilcoxon and Friedman tests. Teachers considered themselves being far from the highest level of abilities they wanted to achieve, and they said having greater control to the design and implementation of learning experience that the conceptual and theoretical references of adult learning. Teachers considered themselves having less than the ideal abilities to facilitate learning.

DESCRIPTORS: Nursing; Higher education; Nursing teachers; Educational models.
\end{abstract}

\section{EVALUACIÓN DE LAS COMPETENCIAS DE LOS PROFESORES DE ENFERMERÍA PARA FACILITAR EL APRENDIZAJE DE ADULTOS}

RESUMEN: El objetivo del estudio fue evaluar el desempeño que el enfermero docente de enfermería atribuye a si mismo, en la competencia de facilitador del aprendizaje de adultos. Es un estudio descriptivo, comparativo, trasversal y cuantitativo, desarrollado con 226 docentes enfermeros de la graduación en enfermería de São Paulo. Los datos fueron obtenidos de junio de 2010 a febrero de 2011, por medio de escala de Likert, puestos en planilla de Excel $^{\circledR} \mathrm{y}$ analizados por estadística descriptiva y testes no paramétricos de Wilcoxon y Friedman. Los profesores se consideraron distantes del nivel máximo de las competencias que deseaban alcanzar, declararon mayor dominio para el design y aplicación de experiencias de aprendizaje que de la estructura conceptual y teórica del aprendizaje de adultos. Los docentes se consideraron inferiores al ideal en las competencias para facilitar el aprendizaje.

DESCRIPTORES: Enfermería; Educación superior; Docentes de enfermería; Modelos educacionales.

*Artigo extraído da dissertação de mestrado intitulado: "Competências Andragógicas dos Docentes Enfermeiros que Atuam na Graduação em Enfermagem Paulistana." Universidade Federal de São Paulo, 2011. 


\section{INTRODUÇÃO}

A educação de adultos sempre esteve articulada às transformações sociais e evolução do homem, à percepção sobre si e de seu amadurecimento(1). A Andragogia, teoria que surgiu nesse contexto, consagrou-se em 1968, quando Malcom Knowles passou a utilizá-la para nomear a teoria e a prática da educação de adultos ${ }^{(2-5)}$.

Pesquisas sobre a Andragogia na saúde e na enfermagem demonstraram que se trata de um tema impactante e que deverá se manter em destaque no futuro ${ }^{(6-7)}$. Nos países latinoamericanos, o uso da Andragogia iniciou-se com o projeto da Fundação W. K. Kellogg, denominado "Uma Nova Iniciativa na Formação dos Profissionais de Saúde: União com a Comunidade - UNI", que estimulou o intercâmbio de metodologias de ensino entre países latinoamericanos, a partir da década de $1990^{(8)}$.

Uma das vantagens do modelo andragógico aplicado à Enfermagem é estimular o enfermeiro educador de adultos a mudar sua atitude na relação de ensino, tornando-se coadjuvante. Essa mudança de atitude condiz com as orientações das Diretrizes Curriculares do Curso de Enfermagem ${ }^{(9)}$, que objetiva promover, no estudante, a competência do desenvolvimento intelectual e profissional autônomo e permanente.

Em 1981, Knowles publicou a "escala de classificação autodiagnóstica para a educação de adultos", com base em três categorias de competências que o professor deveria desenvolver para atuar com adultos: facilitador da aprendizagem, desenvolvedor, e administrador de programas educativos para adultos ${ }^{(5)}$ (Figura 1).
No presente trabalho, foi abordada a competência dos professores para facilitar a aprendizagem de adultos que envolve quatro domínios: estrutura conceitual e teórica da aprendizagem de adultos, design e aplicação de experiências de aprendizagem, auxílio para aprendizes se tornarem auto-dirigidos, e capacidade do professor para selecionar métodos, técnicas e materiais para o programa educativo ${ }^{(2,5)}$.

Ensinar é um dos processos de trabalho do enfermeiro(10), sustentado por leis, decretos e diretrizes que recomendam a formação, a educação permanente de enfermeiros e a adaptação constante às mudanças e à vida em sociedade.

Diante do exposto, questiona-se: "O enfermeiro docente de nível superior domina as competências necessárias para facilitar a aprendizagem de adultos na perspectiva andragógica?"

O índice de crescimento de escolas de formação de enfermeiros no Brasil aumentou consideravelmente desde 1990. Conforme dados do Ministério da Educação (MEC) ${ }^{(11)}$, de 1991 a 2004, em São Paulo, houve crescimento de 263,3\% em número de cursos e, por consequência, o número de docentes aumentou para atender à demanda. Questiona-se se esse aumento súbito foi suficiente para estimular esses docentes a se formarem com as competências necessárias para educar adultos, na graduação em enfermagem. Acrescenta-se que, de 2004 a 2007, houve crescimento de $39,3 \%$ de estudantes e de $34,8 \%$ de cursos em todo território brasileiro ${ }^{(12)}, \mathrm{o}$ que também pode ter estimulado a busca pela formação docente.

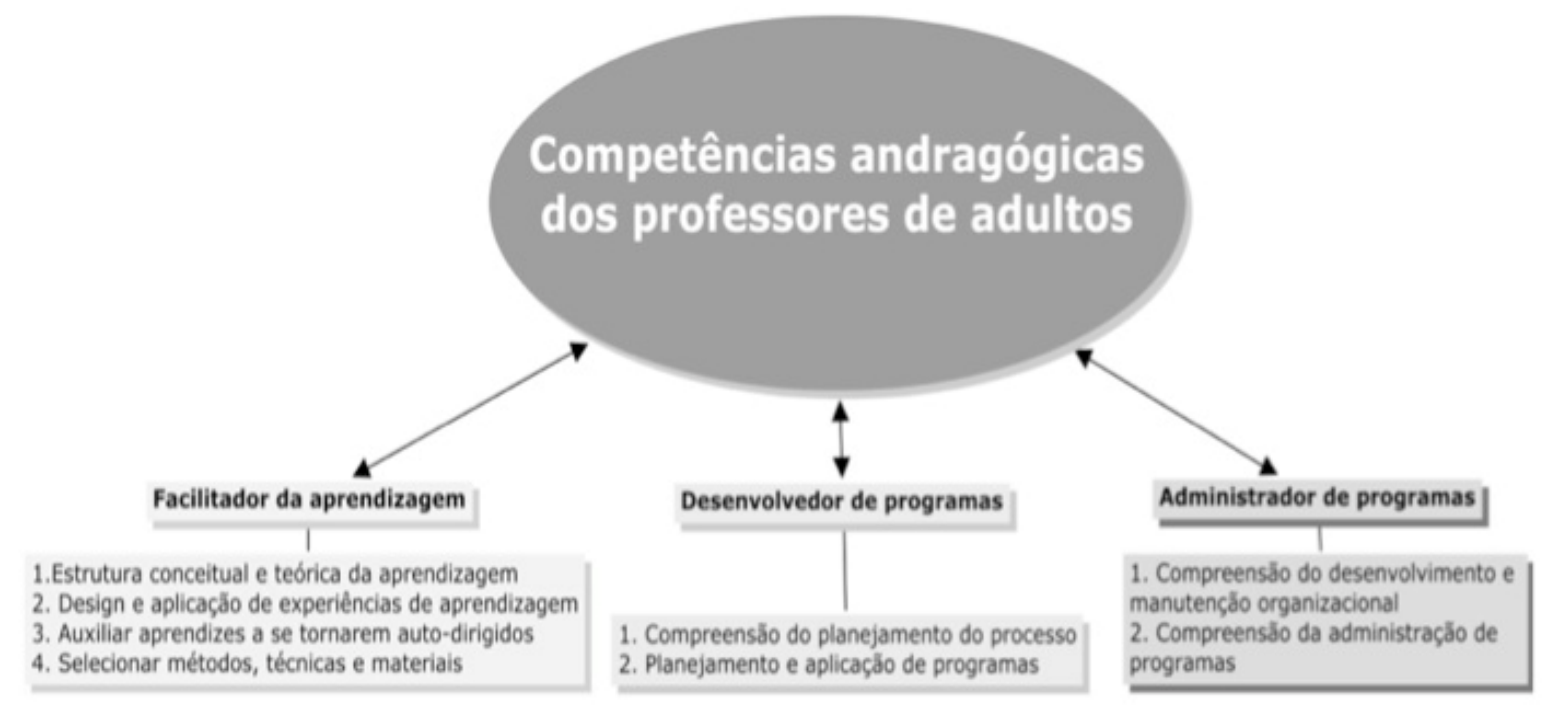

Figura 1 - Mapa conceitual sobre as competências para a educação de adultos segundo Knowles. São Paulo, 2011 
A estrutura das escolas também é uma preocupação, uma vez que os dados do MEC, com relação ao Exame Nacional de Desempenho dos Estudantes (Enade), permitiu observar que há problemas na formação de enfermeiros, visto que a média geral da Enfermagem (31,9\%) foi inferior à média geral da Saúde (32,3\%), em $2004^{(11)}$. O comportamento do Enade ${ }^{(13)}$ de 2007 foi semelhante ao de 2004: o resultado geral mostrou que o rendimento médio geral ficou abaixo do desejado, indicando situação preocupante e necessidade de reflexão sobre a efetividade das práticas educativas. As notas do Enade objetivam refletir o desempenho dos estudantes e o grau de domínio das diversas competências, saberes e conteúdos previstos nas Diretrizes Curriculares Nacionais ${ }^{(9)}$. Notas baixas podem indicar formação profissional de enfermeiros aquém das recomendações do MEC e das competências necessárias para atuar profissionalmente. Mais tarde, essa formação certamente irá se refletir negativamente no desempenho dos processos de trabalho do enfermeiro, sendo que sua formação só pode se dar, com qualidade, em escolas que tenham essa preocupação.

Escolas que promovem boa formação são representadas por pessoas que desejam ensinar (docentes) eoutrasquedesejamaprender(alunos); por esse motivo, olhar para o professor e para as competências que este deve deter, no contexto atual, é muito importante. Bons enfermeiros são formados por docentes competentes, no caso, que detenham as competências para facilitar e promover a aprendizagem de adultos.

Por fim, ressalta-se que, na literatura brasileira, há poucos estudos que abordem competências de professores para trabalhar com educação de adultos. Na Enfermagem, não há estudos que mensurem as competências de professores enfermeiros que atuam na graduação de enfermagem na perspectiva andragógica. Assim, justifica-se a realização da presente pesquisa.

A presente pesquisa teve como objetivo identificar como o enfermeiro docente de enfermagem avaliou as competências que possuía para facilitar a aprendizagem de adultos e quais considerava ideal ter, e comparar as competências que o docente dizia que possuía com as que considerava ideal ter.

\section{MÉTODO}

Estudo descritivo e comparativo, transversal, com abordagem quantitativa, que foi desenvolvido junto aos cursos de Graduação em Enfermagem presenciais, autorizados e funcionantes no município de São Paulo em 2010. Segundo dados do $\mathrm{MEC}^{(14)}$, nesse ano havia 27 cursos nessa condição e participaram no presente estudo 20 instituições de ensino superior. Foram excluídos quatro cursos por não terem, no momento da pesquisa, turmas em andamento, um por recusar-se a participar, dois por não retornarem às solicitações e um, por ter curso superior de enfermagem exclusivamente na modalidade de ensino à distância, não atendendo ao critério de inclusão.

A população do estudo compreendeu enfermeiros professores de cursos de graduação presenciais em Enfermagem que estavam localizados e funcionando no município de São Paulo; que possuíssem, no mínimo, um curso de graduação presencial em Enfermagem com pelo menos dois anos de funcionamento e estivesse em atividade, e autorizassem, por meio de seus diretores/coordenadores, a abordagem do corpo docente. Os docentes que compuseram a população assinaram o termo de consentimento livre e esclarecido (TCLE); não estavam afastados de suas atividades e exerciam a atividade docente, no nível superior, por um período superior a seis meses.

O projeto obedeceu à Resolução 196 do Conselho Nacional de Saúde do Ministério da Saúde (MS), de 1996, vigente na época da coleta de dados, tendo sido submetido ao Comitê de Ética em Pesquisa com Seres Humanos da Universidade Federal de São Paulo (UNIFESP), sendo aprovado sob o número 1620/10.

O contato com o corpo docente partiu da informação fornecida pelos coordenadores dos cursos, que forneceram o número total de docentes ou população, somando 653 sujeitos. Foram distribuídos 653 questionários e retornaram $226(34,61 \%)$ instrumentos respondidos e com TCLE assinados.

O instrumento de coleta de dados foi composto de duas partes: dados de caracterização da população (idade, sexo, carga horária semanal de trabalho, tempo de docência, formação, pós graduação lato e estrito senso) e escala de medida tipo Likert, sobre competências para o papel do educador/instrutor de adultos. A escala utilizada foi proposta e testada por Malcom Shepherd Knowles, e a permissão de seu uso é garantida sem limitações ${ }^{(2)}$.

O instrumento em questão, denominado 
"Escala de classificação autodiagnóstica de competências para o papel do educador de adultos", se compõe de três agrupamentos de competências que somam 54 asserções. O agrupamento ou competência para facilitação da aprendizagem foi o foco desse artigo e pode ser compreendido em quatro domínios: I estrutura conceitual e teórica da aprendizagem de adultos, II - design e aplicação de experiências de aprendizagem, III - auxiliar aprendizes a se tornarem autodirigidos, e IV - selecionar métodos, técnicas e materiais. Cada domínio apresentava um conjunto de habilidades.

A cada descrição de habilidade correspondia uma escala de medida de seis gradações, ou seja, 0 - ausente, 1 - muito baixo conhecimento, 2 - baixo conhecimento, 3 - moderado conhecimento (Compreensão conceitual), 4 alto conhecimento e 5 - altíssimo conhecimento (expert ou especialista). Assim, o docente sujeito da pesquisa anotou, utilizando a letra " $A$ ", o ponto em que avaliava se encontrar atualmente, e a letra " $\mathrm{D}$ ", onde desejava estar, para atuar com adultos em processos de ensino e aprendizagem.

A coleta de dados se iniciou em junho de 2010, após a obtenção da autorização dos diretores/coordenadores dos cursos e mediante a assinatura do TCLE pelos docentes e encerrouse em fevereiro de 2011.

As informações foram coletadas por meio do instrumento descrito e foram transcritas para um banco de dados construído com a ferramenta Excel $^{\circledast}$, composto por 119 colunas, com os dados de caracterização da população e resultados da escala. Após preenchido o banco, os dados da planilha foram transportados para software para tratamento estatístico denominado Minitab ${ }^{\circledR}$ versão 16. No presente texto, apenas os dados de caracterização da população e a parte da escala referente às competências em foco serão relatados.

A análise da população do estudo empregou estatística descritiva - frequência simples (número absoluto) e relativa (porcentagem), medidas de tendência central e de variabilidade, ou seja, média, mediana, desvio padrão, valor mínimo e máximo ${ }^{(15-16)}$.

Os dados da escala de avaliação autodiagnóstica para o papel de educador de adultos foram tratados em três etapas: 1. Os níveis atual e desejado dos docentes enfermeiros para cada habilidade que compõe os domínios de uma determinada competência são significantes.
2. Os níveis atual e desejado dos docentes enfermeiros para as habilidades dentro de cada domínio isoladamente (I, II, III e IV) e 3. Os níveis atual e desejado dos docentes enfermeiros para as habilidades entre os domínios. Como as habilidades de cada competência não seguiam um padrão, utilizou-se testes não paramétricos para avaliar a significância.

Assim, cada linha da escala foi tratada separadamente, utilizando estatística descritiva - soma, proporção (\%), média, desvio padrão, mínimo, mediana e máximo e, após, para a comparação entre os níveis de competência atual ("A") e desejado ("D"), utilizou-se o teste não paramétrico de Wilcoxon ${ }^{(15-16)}$ para a primeira e segunda etapa, e Friedman ${ }^{(15-16)}$ para a terceira. O índice de significância, que determinou se o grau de diferença entre elas era ou não relevante, foi considerado para os valores de $\mathrm{P}<0,05$ ou $5 \%$.

Os dados que resultaram da análise detalhada acima foram confrontados com a literatura sobre o assunto.

\section{RESULTADOS}

Os 226 professores (Tabela 1), tinham entre 27 e 67 anos, sendo que 119 (52,65\%) tinham entre 41 a 55 anos e eram, na maioria, 198 (87,61\%), do sexo feminino, 158 (69,91\%), trabalhavam de 31 a 40 horas semanais e tinha de seis a 10 anos de docência. Que atuavam em disciplinas teóricas e práticas foram $176(77,88 \%)$. Em relação à formação (Tabela 2), $122(53,98 \%)$ se formaram em escola pública, 201 (88,94\%) fizeram especialização, principalmente em Educação, Administração e Saúde Materno-infantil, 180 (79,65\%) fizeram mestrado, principalmente em Enfermagem em Saúde do Adulto e também em Administração, $77(34,07 \%)$ professores eram doutores, principalmente em Enfermagem, apenas três $(1,33 \%)$ declararam serem livres-docentes e 28 $(12,39 \%)$ cursaram outra graduação.

O tratamento dos dados da escala de classificação autodiagnóstica para o papel de facilitador de aprendizagem de adultos, permitiu constatar que, com relação à competência de facilitador da aprendizagem, no domínio Estrutura conceitual e teórica da aprendizagem de adultos, os docentes, embora tenham pontuado que estavam aquém do nível desejado da competência (índice de significância 0,0000), sinalizaram que detinham competência atual (A) moderada e desejavam (D) mais habilidade para conceituar e explicar o papel do professor como 
Tabela 1 - Docentes enfermeiros segundo variáveis sociodemográficas, tempo de atuação, carga horária e tipo de disciplina que ministrava. São Paulo, SP, Brasil, 2011

\begin{tabular}{|c|c|c|}
\hline Variável & $\begin{array}{l}\text { Frequência } \\
\text { (total=226) }\end{array}$ & $\%$ \\
\hline \multicolumn{3}{|l|}{ Faixa etária } \\
\hline 41 a 55 anos & 119 & 52,65 \\
\hline \multicolumn{3}{|l|}{ Sexo } \\
\hline Feminino & 198 & 87,61 \\
\hline \multicolumn{3}{|c|}{ Carga horária e tempo de docência } \\
\hline 31 a 40 horas/ 6 a 10 anos & 158 & 69,91 \\
\hline \multicolumn{3}{|l|}{ Tipo de disciplina } \\
\hline Teórica e prática & 176 & 77,88 \\
\hline
\end{tabular}

Tabela 2 - Docentes enfermeiros segundo formação e educação permanente. São Paulo, SP, Brasil, 2011

\begin{tabular}{lcc} 
Variável & Frequência & $\%$ \\
\cline { 2 - 3 } & (total=226) & \\
\hline Formação & & \\
\hline Escola pública & 122 & 53,98 \\
\hline Escola privada & 101 & 44,69 \\
\hline Não informado & 3 & 1,33 \\
\hline PG Latu-senso & 201 & 88,94 \\
\hline PG Stricto-senso & & \\
\hline Mestrado & 180 & 79,65 \\
\hline Doutorado & 77 & 34,07 \\
\hline Livre-docência & 3 & 1,33 \\
\hline Outras graduações & & \\
\hline Sim & 28 & 12,39
\end{tabular}

facilitador e fonte de recursos para aprendizes autodirigidos (média $A=3,17$ e média $D=4,72$ ) do que habilidade para descrever teorias de aprendizagem e avaliar sua relevância para as situações específicas de aprendizagem de adultos (média $A=2,23$ ). Também em relação ao desejo, a escala de menor pontuação foi habilidade para descrever as diferenças entre jovens e adultos como aprendizes, e as implicações dessas diferenças para o ensino (média $\mathrm{D}=4,40$ ).

Ainda na competência de facilitador da aprendizagem, no domínio design e aplicação de experiências de aprendizagem, a menor habilidade foi atribuída à capacidade de descrever a diferença entre planos de conteúdo com relação a desenhos de processos. Esta também foi a que menos desejavam desenvolver (média $A$ $=2,40$ e média $\mathrm{D}=4,43$ ). Os docentes sinalizaram ter mais habilidade para criar ambientes (físico e psicológico) de respeito, confiança, sinceridade, apoio e segurança mútuos, sendo esta habilidade que eles mais desejavam desenvolver (média $\mathrm{A}=$ 3,61 e média $D=4,86$ ).

Para o terceiro domínio da competência de facilitador da aprendizagem, denominada auxiliar aprendizes a se tornarem autodirigidos, o maior e também o menor desejo de desenvolverse encontrado foi na habilidade para modelar seu papel de aprendizagem autodirigida em seu próprio comportamento (média $\mathrm{A}=2,58 \mathrm{e}$ média $D=4,46)$. $O$ menor domínio sinalizado foi para a habilidade de planejar e conduzir experiências de aprendizagem autodirigidas (média $A=2,53$ ). A habilidade que os professores mais desejavam desenvolver foi a de explicar a diferença conceitual entre instrução didática e aprendizagem autodirigida (média $\mathrm{D}=4,52$ ). Vale destacar que as diferenças entre o nível atual (e também entre o nível desejado da competência), dentre as habilidades deste domínio, foram muito próximas, praticamente empatadas.

Por fim, no domínio IV da competência de facilitador da aprendizagem, denominada selecionar métodos, técnicas e materiais, a habilidade de menor domínio, com relação às outras deste rol, foi a de construir e usar ferramentas e procedimentos para a avaliação de necessidades de desenvolvimento de competências (média $A=2,56$ ), enquanto a de maior domínio foi a habilidade para usar dinâmicas de grupos e técnicas de pequenos grupos de discussão (média $A=3,14$ ). $O$ maior desejo de desenvolver-se foi sinalizado com relação à habilidade para inventar novas técnicas de maneira a adaptá-las às novas situações (média $\mathrm{D}=4,75)$, e a de menor desejo foi a habilidade para usar métodos de participação de audiência (média $\mathrm{D}=4,50$ ).

O resultado da relação entre as questões de cada domínio permitiu identificar que os docentes estavam aquém do que desejavam alcançar (índice de significância $(P)=0,0000$ ), concentrando as respostas na escala em três para atual (A) e cinco para desejado (D).

Com relação aos índices de significância entre os domínios, observou-se que houve relevância na relação entre os domínios da competência de facilitador da aprendizagem. A habilidade, por domínio, teve menor ênfase na estrutura conceitual e teórica da aprendizagem de adultos (I) (mediana $A=2,60$ ) e maior ênfase para design e aplicação de experiências de aprendizagem (II) (mediana $\mathrm{A}=3,07$ ). O desejo em desenvolver-se, 
por domínio, teve menor ênfase para estrutura conceitual e teórica da aprendizagem de adultos (I) (mediana $A=4,60$ ) e maior ênfase para design e aplicação de experiências de aprendizagem (II) (mediana $A=4,85$ ). Esses dados podem ser observados na Figura 2.

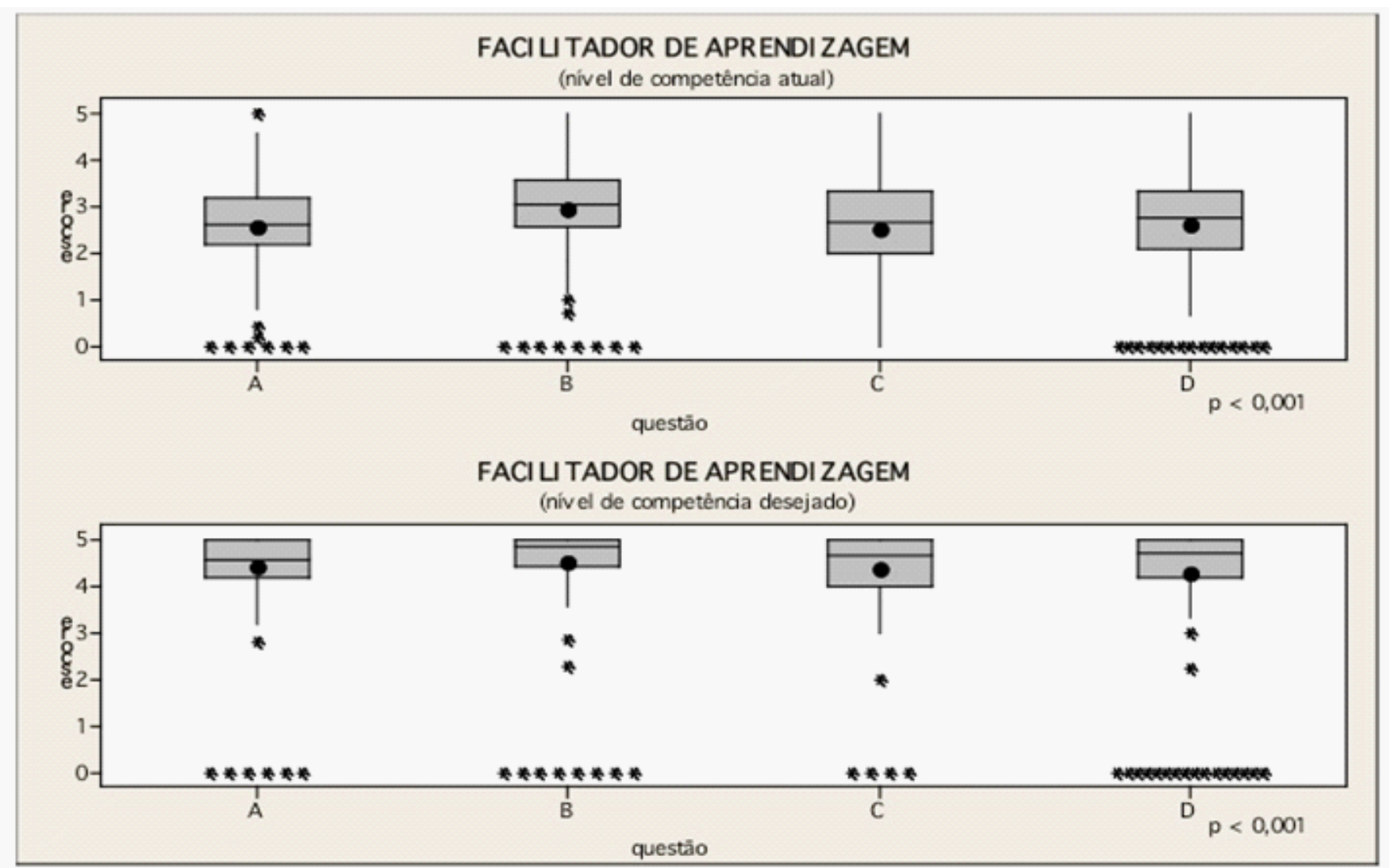

Figura 2 - Resultados sobre a competência "Facilitador da Aprendizagem", relação entre domínios, nível atual e desejado para educação de adultos segundo os docentes enfermeiros que atuam na graduação em enfermagem no município de São Paulo, 2011.

\section{DISCUSSÃO}

Quanto aos dados de identificação, tratou-se predominantemente de uma população feminina, de meia idade, com pós-graduação, que atua em regime de aproximadamente 40 horas semanais e que ministra disciplinas teóricas e práticas.

Sobre a competência de facilitador da aprendizagem, discutida a seguir, para todos os domínios a maior parte dos professores declarou domínio moderado e desejo máximo de desenvolver-se.

Estrutura conceitual e teórica da aprendizagem de adultos

A Andragogia não é um processo que enfatiza o conteúdo, como a teoria tradicional. Pelo contrário, sua proposta está em enfatizar a aquisição de competências e a autodireção do aluno. Dessa forma, para facilitar a aprendizagem, é essencial que o professor torne-se hábil para reconhecer e manejar as necessidades, interesses, motivações, capacidades e características dos adultos como aprendizes. Para tanto, o professor deve se adaptar às características do aluno reconhecendo seu grau de maturidade e a heterogeneidade existente em cada sala de aula.

Grande parte dos professores aprendeu ao longo de sua vida por meio da teoria tradicional ou pedagogia, e não detém experiência na condução e facilitação da aprendizagem de adultos por meio da concepção andragógica. Além disso, os professores têm pouco preparo para a área de ensino, fundamentam suas atividades pautadas em modelos que tiveram quando alunos e valorizam o domínio do conteúdo a ser ensinado $^{(17)}$. Talvez cursos e disciplinas voltados aos temas de ensino e aprendizagem, oferecidos na formação de mestres e doutores e também em cursos de licenciatura possam contribuir com o desenvolvimento de habilidades para o ensino de adultos, mas nem todos os professores tem acesso a eles.

\section{Design e aplicação de experiências de aprendizagem}

Os professores estão habituados a trabalhar com conteúdos, pois a pedagogia valoriza o conhecimento. $\mathrm{O}$ enfoque no processo de 
ensino e aprendizagem e o uso de recursos metodológicos não são habituais na prática cotidiana de professores que aprenderam a valorizar conteúdos. $\mathrm{O}$ processo de ensino e aprendizagem e, portanto, o uso de recursos metodológicos requer que o professor reconheça que cada aprendiz tem experiências prévias que deverão ser consideradas para planejar propostas que considerem essas experiências como um ponto de partida, além de envolver grande capacidade de adaptação, criatividade e domínio de recursos diversos. Sem dúvida essa é uma tarefa desafiadora para professores conteudistas.

Ambientes amigáveis são promovidos por professores que facilitam a adaptação dos aprendizes, de forma a orientar e acompanhar rotinas, considerar a experiência prévia, planejar programa de ensino e envolver o aluno nesse planejamento, inserindo repetições, períodos de descanso, escolhas, oferta de feedback diário, estímulo à autoavaliação e encorajamento de pontos fortes ${ }^{(18)}$. Nesse sentido, a formação de enfermeiros tem como essencial as habilidades nas relações interpessoais; dessa forma, partese da premissa que o enfermeiro detém essa habilidade, que é uma experiência anterior que influenciará o exercício da docência.

\section{Auxiliar aprendizes a se tornarem autodirigidos}

A tarefa de preparar o aprendiz para a autodireção foi acrescentada ao processo andragógico em 1995 por Knowles ${ }^{(2)}$, devido ao alto grau de responsabilidade que o aprendiz teria que assumir em tornar-se autodirigido e, também, ao sucesso da aprendizagem com o aprendiz tornando-se sujeito de seu processo educativo. A autodireção estimula que o estudante desenvolva a autoconfiança e independência para aprender, porém há limites que devem ser considerados na tarefa de conduzir o aluno à autodireção.

O aprendiz, no contexto atual, não está preparado para assumir a autodireção e tampouco desenvolveu postura questionadora e autodirigida, pois, ao longo de sua trajetória educativa, aprendeu sob o alicerce da pedagogia clássica. Isso gera choques culturais, quando expostos a programas que exigem a autodireção. Para minimizar esse fato, professores andragógicos devem incorporar módulos, disciplinas ou cursos preparatórios sobre autodireção, que envolvem as diferenças entre aprendizagem proativa e reativa, investigação sobre os recursos dos aprendizes (experiências anteriores), estabelecimento de relações interpessoais com pequenos grupos e exercícios de autodireção ${ }^{(3)}$. Essas talvez sejam tarefas pouco comuns, na realidade dos sujeitos do presente estudo e, talvez, por dominá-las menos, é que desejavam desenvolvê-las mais.

\section{Selecionar métodos, técnicas e materiais}

Técnicas de aprendizagem ativas, ou seja, que exigem que o aluno reflita, pratique, critique e se envolva, permitem, ao educador e ao aluno, observar o progresso do aprendizado por meio da habilidade demonstrada com o assunto. O domínio de técnicas, métodos e materiais está diretamente relacionado com os estilos e características de aprendizagem dos alunos adultos, ou seja, cada indivíduo processa informações de forma diferente ${ }^{(19)}$. O professor deve ser consciente desse fato e adaptar o ensino à realidade dos alunos. Desta forma, selecionar métodos também implica em conhecer o aprendiz e assumir diferentes papéis que se adaptem ao nível de amadurecimento do aluno ${ }^{(17)}$.

O domínio de métodos, técnicas e materiais reúne um grupo de competências do facilitador da aprendizagem que objetiva que o aluno adquira habilidades por meio do reforço cognitivo e psicomotor sobre o tema. Um relato de experiência ${ }^{(20)}$ constatou que alunos tornaram-se mais hábeis e autoconfiantes quando observaram e experimentam métodos práticos de punção venosa. O professor deve ter habilidade para classificar, selecionar e aplicar métodos, técnicas e materiais cabíveis a cada processo de ensinoaprendizagem.

\section{Comparação entre os quatro domínios da competência para facilitação da aprendizagem}

Sobre a percepção atual dos professores entre os quatro domínios das competências para facilitação da aprendizagem, a ponderação entre as respostas permitiu diagnosticar que houve domínio maior do design e aplicação de experiências de aprendizagem e menor para a estrutura conceitual e teórica da aprendizagem de adultos. Isso pode estar vinculado à prática de metodologias, ainda que por poucos docentes, como a problematização, a aprendizagem baseada em problemas, o uso de contratos de aprendizagem, do portfólio e do ensinoà distância, como movimentos em resposta à necessidade de investir na formação de profissionais mais críticos, reflexivos e proativos.

Em contrapartida, a fundamentação da prática educativa ainda é predominantemente pedagógica tradicional, respondendo ao menor domínio da teoria de aprendizagem de adultos. Há também que se retomar a questão da formação 
docente estar pautada na pós-graduação senso estrito e negligenciar temas de ensino e, assim, os professores perpetuarem modelos que tiveram quando alunos.

Os professores experimentam atualmente um processo de transição do ensino tradicional para modelos e teorias que atendam às necessidades do aluno, pois assim a aprendizagem tem demonstrado maiores e melhores resultados. Para tanto, o professor deve dominar também o processo de ensino que, na educação de adultos, envolve a estrutura conceitual e teórica da aprendizagem de adultos, o design e aplicação de experiências de aprendizagem, programas de autodireção e métodos, técnicas e materiais. Isso implica em focar o processo de ensino no sujeito que aprende.

A teoria de aprendizagem de adultos tem documentado seu sucesso por atender às demandas cognitiva (intelectual), afetiva (emocional) e psicomotora do aluno (experiência) (21).

\section{CONSIDERAÇÕES FINAIS}

O presente estudo apurou a competência para facilitar a aprendizagem de adultos segundo os docentes que atuavam na graduação de enfermagem paulistana, por meio da escala de classificação autodiagnóstica de competências andragógicas para o papel do educador de adultos, desenvolvida por Knowles. O instrumento demonstrou que avalia o perfil dos professores com relação às competências para atuar na educação de adultos.

De maneira geral, os sujeitos desse estudo declararam estar em nível intermediário em comparação ao máximo que desejava atingir dos agrupamentos de competências de facilitador de aprendizagem, ou seja, grande parte dos docentes enfermeiros encontrava-se distante do ideal de nível máximo de competência que almejava. Assim, como esse grupamento valoriza e influencia consideravelmente $\mathrm{o}$ sucesso da aprendizagem na enfermagem, sugere-se a intervenção nos processos de formação e aperfeiçoamento do professor de enfermagem, nessas competências, para a melhoria do ensino.

A análise global dos resultados indica que, antes que qualquer intervenção que considere a Andragogia como fundamento para a formação de professores seja implementada, há que se mensurar o nível atual de competências desses indivíduos. Isso foi feito na presente pesquisa justamente porque não há, na Enfermagem, mensurações de competências na perspectiva andragógica.

Os limites desse estudo devem ser considerados pelos leitores e pesquisadores, visto que se trata se um trabalho realizado em escolas e agrupamentos de professores característicos da cidade de São Paulo e que não cabem a outras realidades distintas dessa.

Considera-se que o estudo será útil para facilitar o planejamento de programas para desenvolvimento individual e institucional de professores e de instituições de ensino pelos administradores, com relação às competências relevantes para aumentar a performance de docentes e alunos.

\section{REFERÊNCIAS}

1. Luckesi CC. Filosofia da educação. São Paulo: Cortez; 2003.

2. Knowles MS, Holton EF, Swanson RA. Aprendizagem de resultados: uma abordagem para aumentar a efetividade da educação corporativa. Rio de Janeiro: Elsevier; 2009.

3. Knowles MS. Self-directed learning: a guide for learners and teachers. New York: Cambridge Adult Education, Globe Fearon; 1975.

4. Knowles MS. The making of an adult educator: an autobiographical journey. San Francisco: JosseyBassey; 1989.

5. Knowles MS. The modern pratice of adult education: andragogy versus pedagogy. Chicago: Association Press; 1970.

6. Draganov PB, Friedlander MR, Sanna MC. Andragogiana saúde: estudo bibliométrico. Esc. Anna Nery. 2011; 15(1):149-56.

7. Draganov PB, Carvalho AA, Sanna MC, Neves VR. Andragogia na enfermagem: uma revisão da literatura. Campo Grande: Associação Brasileira de Enfermagem. Anais do $16^{\circ}$ Seminário de Pesquisa de Enfermagem. Campo Grande (MS): ABEn; 2011 [acesso em 15 set 2011]. Disponível: http://www.abeneventos.com. br/16senpe/senpe-trabalhos/files/0530.pdf

8. Machado JLM, Caldas Junior AL, Bortoncello NMF. Uma nova iniciativa na formação dos profissionais de saúde. Interface, Comun., Saúde, Educ. 1997; 1(1):14756.

9. Ministério da Educação (BR). Resolução CNE/CES, $\mathrm{n}^{\circ} 3$, de 7 de novembro de 2001. Institui diretrizes curriculares nacionais do curso de graduação em 
enfermagem. Brasília; 2011.

10. Sanna MC. Os processos de trabalho em enfermagem. Rev. bras. enferm. 2007; 60(2):221-4.

11. Instituto Nacional de Pesquisas Educacionais (INEP). A trajetória dos cursos de graduação na saúde 1991-2004: Enfermagem. Brasília: INEP; 2006.

12. Ministério da Educação (BR). Sistema Nacional de Avaliação da Educação Superior (Sinaes). [Internet] Brasília: Ministério da Educação [acesso em 15 mai 2011]. Disponível: http://portal.inep.gov.br/superiorsinaes

13. Ministério da Educação (BR). Exame Nacional de Desempenho de Estudantes (Enade). [Internet] Brasília: Ministério da Educação [acesso em 15 mai 2011]. Disponível: http://portal.inep.gov.br/enade

14. Ministério da Educação (BR). Instituições de Educação Superior e Cursos Cadastrados. [Internet] Brasília: Ministério da Educação; 1997 [acesso em 15 maio 2010]. Disponível: http://emec.mec.gov.br

15. Siegel S. Estatística não paramétrica para ciências do comportamento. São Paulo: McGraw-Hill; 1956.

16. Altman DG. Practical statistics for medical research. London: Chapman\&Hall, CRC; 1999.

17. Thompson JE. Competencies for midwifery teachers. Midwifery. 2002; 18(4):256-9.

18. Hohler SE. Creating an conducive to environment adult learning. AORN Journal. 2003; 77(4):833-5.

19. Potts DA, Davis KF. Making education stick!. J Emerg Nurs. 2009; 35(4):375-8.

20. Souers C, Kauffman L, McManus C, Parker V. Collaborative learning: a focused partnership. Nurse Educ Pract. 2007; 7(6):392-8.

21. Graling PL, Rusynko B. Implementing a perioperative: nursing fellowship program. AORN Journal. 2001; 73(5):939-45. 